\title{
Biochemical composition of washed human seminal coagulum in comparison to sperm-free semen from the same donors
}

\author{
A. Mandal and A. K. Bhattacharyya \\ Reproductive Biology Laboratory, Department of Biochemistry, Calcutta University \\ College of Science, 35 Ballygunge Circular Road, Calcutta 700 019, India
}

\begin{abstract}
Summary. Intra-individual inter-ejaculate variations in the amounts of protein, fructose, $\mathrm{N}$-acetylamino sugar, phosphate, sialic acid and amino sugar in washed coagulum from normal ejaculates of men were highly consistent $(\mathrm{N}=9)$. All the prostatic components studied (acid phosphatase, zinc, calcium and citric acid), except zinc, in the washed coagulum were reduced by $90 \%$ of their values in semen $(\mathrm{N}=5)$. The seminal vesicular markers (fructose, $\mathrm{N}$-acetylamino sugar and phosphate) had no association with the coagulum structure and represented the soluble components $(\mathrm{N}=5)$. The concentrations of protein and zinc in the coagulum were higher than those of semen by $114 \%$ and $32 \%$ respectively. The coagulum contained sialic acid and amino sugar as integrated components.
\end{abstract}

Keywords: semen; sialoglycoprotein; zinc; coagulum; man

\section{Introduction}

Freshly ejaculated human seminal plasma is mainly a heterogeneous mixture of vesicular coagulum and prostatic liquid contribution. However, within $30 \mathrm{~min}$ of emission, the structural coagulum protein becomes liquefied in vitro by the prostatic hydrolases. The importance of seminal coagulation in the control of human fertility is yet to be established (Tauber et al., 1978). Poorly coagulating ejaculates possess significantly lower concentrations of protein, fructose, $\mathrm{N}$-acetylamino sugar, choline, phosphate, sialic acid and amino sugar than do samples that coagulate normally (Mandal \& Bhattacharyya, 1985a, b, c, 1986a, b, 1987b, c, 1988b, 1990). Some physiological properties of seminal plasma, such as osmotic pressure, buffering capacity and maintenance of sperm motility, were also significantly lower in the poorly coagulating ejaculates (Mandal \& Bhattacharyya, 1988a). Protein, fructose, $\mathrm{N}$-acetylamino sugar and phosphate not only demonstrated significant positive correlations with the degree of coagulation, but also revealed a gradual increase of their concentrations in the parts of the coagulum taking more and more time to liquefy (Mandal \& Bhattacharyya, 1987a). Fructose is believed to play a role in the coagulation of human semen by forming tight bonds with the coagulum protein (Montagnon et al., 1982), but these components have not been examined in the washed human seminal coagulum to determine its integrated components. Studies on the components of washed human seminal coagulum are limited only to amino acid composition, level of basic protein and molecular forms (Koren \& Lukač, 1979; Kusamran \& Surakarnkul, 1983; Lilja \& Laurell, 1985; Lilja et al., 1987).

The objective of the present investigation was to study the biochemical composition of washed human seminal coagulum by following the seminal components which are known to have significant positive correlations with degree of coagulation (i.e. protein, frustose, $\mathrm{N}$-acetylamino sugar, phosphate, sialic acid and amino sugar) and some prostatic marker components (i.e. acid phosphatase, zinc, calcium and citric acid). These components were also measured in whole ejaculates from 
the same men after a similar period of abstinence for comparison with the washed coagulum characteristics.

\section{Materials and Methods}

Chemicals. Methylthymol blue, 1-(2-pyridylazo)-2-naphthol and p-nitrophenylphosphate were purchased from E. Merck (Darmstadt, FRG). Resorcinol, N-acetylglucosamine, glucosamine, $p$-dimethylaminobenzaldehyde, synthetic $\mathrm{N}$-acetylneuraminic acid and thiobarbituric acid were obtained from Sigma Chemical Company (St Louis, MO, USA). Other chemicals were of analytical grade. Double-distilled deionized water was used throughout.

Samples. Semen samples were obtained by masturbation of men ( $28-41$ years of age) in the presence of their wives after an abstinence period of 7 days; the infertile couples were attending the University Hospital of Calcutta. Samples were allowed to liquefy at room temperature. Seminal plasma was obtained by centrifugation at $4 . \mathrm{C}$ at $7000 \mathrm{~g}$ for $30 \mathrm{~min}$ for studying repeat measurements of seminal components. For washed coagulum studies, only sperm-free ejaculates were used (Tables 1 and 2) and the samples were obtained from 2 men producing excretory azoospermic samples and 3 vasectomized men after 4-9 months of voluntary bilateral vasectomies. The volumes of these samples ranged from $2 \cdot 1$ to $3.4 \mathrm{ml}(2 \cdot 8 \pm 0.3 \mathrm{ml}, \mathrm{N}=5)$. All these samples had good coagulum formation and liquefied completely within $20-30 \mathrm{~min}$ of emission. The mean percentage liquefaction, evaluated as described by Mandal \& Bhattacharyya (1987b), of these 5 ejaculates at different times after emission were as follows: $2 \mathrm{~min}-9 \%, 4 \mathrm{~min}-$ $19 \%, 6 \mathrm{~min}-39 \%, 8 \mathrm{~min}-53 \%, 12 \mathrm{~min}-70 \%, 16 \mathrm{~min}-84 \%, 20 \mathrm{~min}-94 \%, 25 \mathrm{~min}-98 \%, 30 \mathrm{~min}-100 \%$. Leucocyte count, using $o$-toluidine following the method of Nahoum \& Cardozo $(1980)$, in these samples was $\leqslant 1 \cdot 0 \times 10^{6} /$ $\mathrm{ml}$. Donors had no history of impotence, cryptorchidism, mumps, orchitis, varicocoele or venereal disease. Prostatic fluid was obtained from men having congenital absence of the vasa deferentia and seminal vesicles (Amelar, 1962; Molnar et al., 1971). Such ejaculates had a liquid consistency, a volume of $<1.0 \mathrm{ml}, \mathrm{pH}<6.5$, no spermatozoa, negligible vesicular markers, and prostatic markers similar to those in prostatic fluid (Kavanagh, 1985).

Preparation of washed coagulum. The selected ejaculates (see samples) were directly collected into $40 \mathrm{ml}$ ice-cold $50 \mathrm{~mm}$-Tris- $\mathrm{HCl}$ buffer $\left(\mathrm{pH} \mathrm{7.5)}\right.$ ) as the coagulum does not liquefy at $0^{\circ} \mathrm{C}$ (Koren \& Lukač, 1979). The mix was then interchanged between two centrifuge tubes 10 times before each centrifugation at $6850 \mathrm{~g}$ for $1 \mathrm{~min}$ in a Servall superspeed centrifuge (type--SSI, Ivan Sorvall Inc., Norwalk, CT, USA) at room temperature. The supernatant (which does not contain the coagulum proteins: Lilja \& Weiber, 1984) was discarded after each washing cycle $(8 \times 40 \mathrm{ml})$. After the last centrifugation, the coagulum was transferred into a precisely graduated tube. The coagulum was then thoroughly homogenized by a glass rod and suspended in $50 \mathrm{~mm}$-acetate buffer $(\mathrm{pH} 5.0)$ or in water equal to the volume of the washed coagulum. This suspension was used without centrifugation for all assays and compared with a separate ejaculate (uncentrifuged) from the same individual. For hydrolysis of the washed coagulum protein, equal volumes of the homogenized coagulum and the prostatic fluid were mixed and incubated at room temperature $\left(30^{\circ} \mathrm{C}\right)$ for $3 \mathrm{~h}$, while individual components were diluted $(\mathrm{l}: 1, \mathrm{v} / \mathrm{v})$ with $50 \mathrm{~mm}$-acetate buffer $(\mathrm{pH} 5 \cdot 0)$.

Biochemical assays. Acid phosphatase activity, and zinc, calcium, citric acid and phosphate (total) levels were determined as described by Mandal \& Bhattacharyya (1987b). Protein, fructose, $\mathrm{N}$-acetylamino sugar and sialic acid contents were assayed as described by Mandal \& Bhattacharyya (1985c). Total amino sugar was assayed by the method of Wagner (1979). A $0.25 \mathrm{ml}$ sample was mixed with $0.25 \mathrm{ml} 8 \mathrm{~N}-\mathrm{HCl}$ and incubated in an oil bath at $120^{\circ} \mathrm{C}$ for $30 \mathrm{~min}$ in a test tube which was stoppered with a glass bead. Then $19.5 \mathrm{ml}$ water were added to the hydrolysate to bring the normality of the mixture to $0.1 \mathrm{~N}$. The mixture was then centrifuged for $10 \mathrm{~min}$ at $3000 \mathrm{~g}$. A sample $(0.8 \mathrm{ml})$ of the supernatant was mixed with $0.6 \mathrm{ml}$ acetylacetone reagent and incubated in a boiling-water bath for $30 \mathrm{~min}$. After cooling the mixture, $2 \mathrm{ml}$ Ehrlich's reagent were added and the absorbance was measured at $535 \mathrm{~nm}$ against a simultaneous blank. Glucosamine $\mathrm{HCl}$ was used as the standard and run regularly for each set of evaluations. Intra- and inter-assay coefficients of variation of this method were $2.0 \%$ and $4.9 \%$ respectively, and recovery was $97 \cdot 4 \%$.

\section{Results}

\section{Repeat measurements of seminal components}

The intra-individual inter-ejaculate variations were studied by measuring the components listed in Table 1 in seminal plasma $(N=5)$, washed coagulum $(N=4)$ and prostatic fluid $(N=4)$ from 2 separate ejaculates after a similar period of abstinence (7 days). No significant variations were noted by paired $t$ test (Richterich, 1969) except for protein in seminal plasma and washed coagulum (variation $<10 \%, P<0.005$ ) and for phosphate in seminal plasma (variation $<5.1 \%, P<0.05$ ). The corresponding values in the washed coagulum with respect to their levels in seminal plasma 


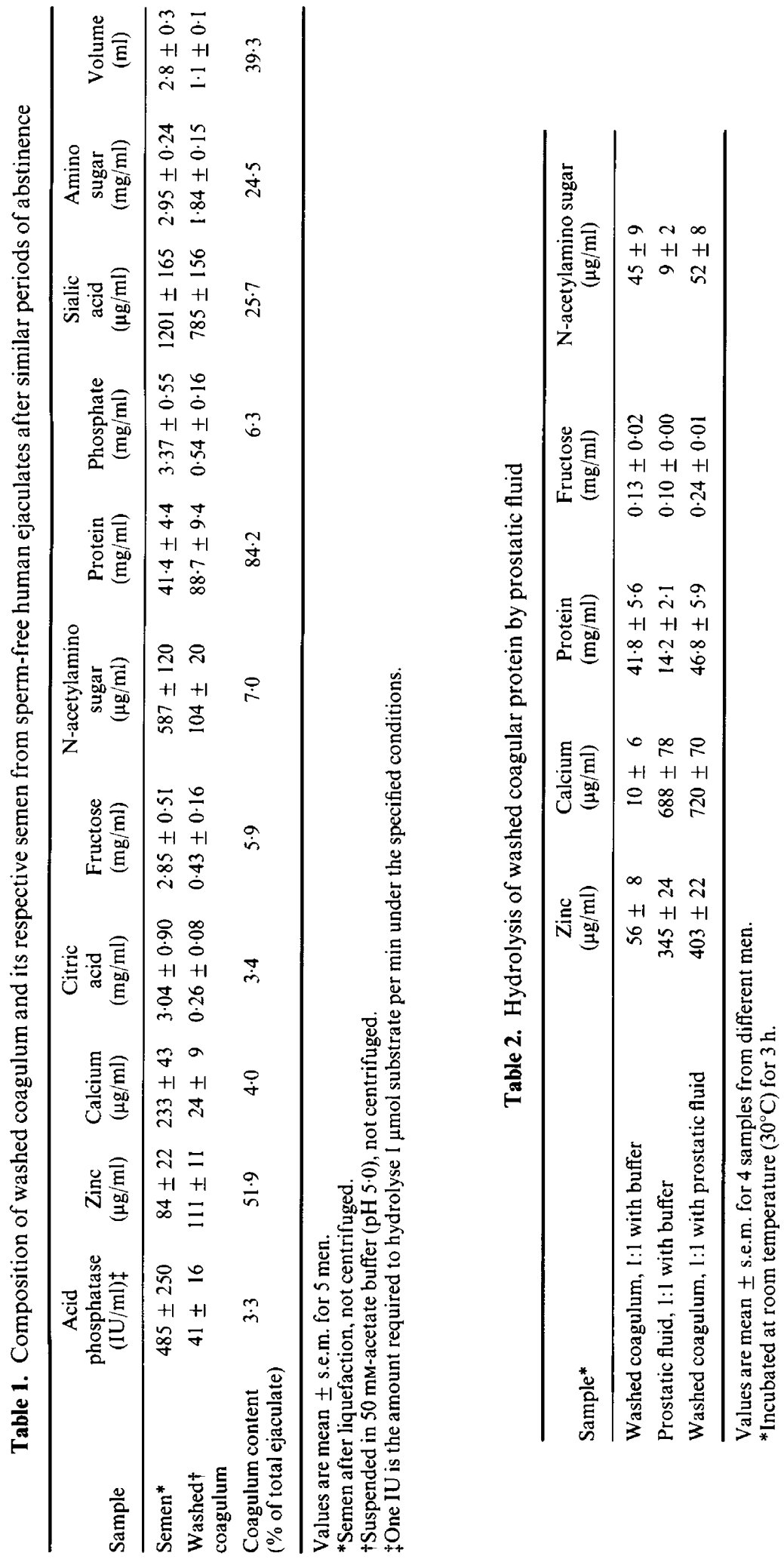


were very consistent. In prostatic fluid, the differences between the initial and repeat measurements were within $5 \%$.

\section{Seminal components in washed coagulum and semen (Table 1)}

The concentrations of acid phosphatase, calcium and citric acid in the washed coagulum were reduced by $90 \%$ of their values in semen. About $84 \%$ reduction of seminal values was also noted for fructose, $\mathrm{N}$-acetylamino sugar and phosphate in the washed coagulum, but the concentrations of zinc and protein in the coagulum part were higher than those of semen by $32 \%$ and $114 \%$ respectively. Coagular sialic acid and amino sugar levels represented about $64 \%$ of their values in semen. All these variations were statistically significant in paired $t$ tests at levels between $P<0.05$ and $P<0.005$, except for zinc and acid phosphatase. Suspension of washed coagulum either in buffer or in water revealed negligible variations $(2 \cdot 3 \pm 0 \cdot 6 \%$, mean \pm s.e.m. $)$ in the concentrations of these 10 components $(\mathrm{N}=4)$.

\section{Incubation of washed coagulum with prostatic fluid (Table 2)}

Homogenized washed coagulum was incubated with prostatic fluid $(1: 1, v / v)$ to cause the hydrolysis of coagular protein (Lilja \& Laurell, 1984, 1985) assuming the incomplete release of fructose (see 'Introduction') from the washed coagular protein in buffer suspension (see Table 1). The recoveries of zinc, calcium, protein, fructose, and $\mathrm{N}$-acetylamino sugar in the mixture after the incubation period were $100 \%, 103 \%, 84 \%, 104 \%$ and $96 \%$ respectively.

\section{Discussion}

To demonstrate the biochemical composition of washed human seminal coagulum, the use of ejaculates from vasectomized and azoospermic men eliminated the possibility of contamination from sperm components. Inter-ejaculate variations were kept to a minimum by using samples from the same men for precise assessment of the differences between semen and washed coagulum. The variation in abstinence period influences the concentrations of seminal components in repeat ejaculates (Mandal \& Bhattacharyya, 1986b), and so in the present investigation all the repeated ejaculates were collected after a similar period of abstinence. From the studies on repeat measurements of seminal components, it is apparent that the components in seminal plasma, washed coagulum and prostatic fluid remained essentially the same in repeated ejaculates as observed earlier for seminal plasma constituents in 12 men following a similar period of abstinence (Mandal \& Bhattacharyya, 1987b).

Removal of prostatic components from the washed coagulum was judged from the levels of prostatic marker components (i.e. acid phosphatase, zinc, calcium and citric acid). These components are also known to occur in the seminal vesicular secretion at a very low concentration, i.e. about $10 \%$ of their values in semen (Bostrom \& Andersson, 1971). Therefore, the washed coagulum samples in the present study can be considered as free from prostatic components since these values in the coagulum were only about $10 \%$ of the values in semen (except for zinc, see Table 1 ). Although in some samples the desired $(90 \%)$ removal of prostatic components was obtained after 5 washings, no differences were found for values for components between the 7 th and 8 th times that the coagulum was washed.

After the washing procedure (see 'Methods'), the concentrations of protein in the washed coagulum were similar to those of the pure seminal vesicle secretion (Beyler \& Zaneveld, 1982) which constitutes the structural protein of coagulated semen (Lilja \& Laurell, 1985). Zinc in human seminal plasma is mainly excreted from the prostate as a low molecular weight complex with citrate. After ejaculation about $50 \%$ of this zinc is redistributed and becomes bound to medium $(3000-80000)$ and high $(>80000)$ molecular weight proteins of vesicular origin (Arver, 1982; 
Kavanagh, 1983). In our study $52 \%$ of the total seminal zinc content (see Table 1) was found in the coagulum-bound form and so indicates that the vesicular zinc binding ligands originally exist as coagulum protein. Moreover, this observation raises a vital question about the role of zinc in the human seminal coagulation process, if any.

Like the prostatic components, fructose, $\mathrm{N}$-acetylamino sugar and phosphate were also removed from the washed coagulum (see Table 1). Montagnon et al. (1982) demonstrated that, after liquefaction of human semen for $30 \mathrm{~min}$ at $37^{\circ} \mathrm{C}$, fructose is almost totally (i.e. $91 \%$ ) dialysable; however, blocking of the liquefaction by exposing semen to acidic conditions (buffer $\mathrm{pH} 2 \cdot 4$ ) renders this sugar non-dialysable. These observations led them to believe that fructose plays a role in the coagulation process of semen possibly by forming covalent linkages with the coagulum proteins. The washed coagulum that did not undergo liquefaction (see 'Methods') may therefore contain bound fructose which could be measured from its protein-free alcohol supernatant (Mandal \& Bhattacharyya, 1985c). To see whether the hydrolysis of the washed coagulum protein by naturally occurring components can cause the release of further fructose, homogenized washed coagulum was incubated with prostatic fluid considering normal proportions in semen (Wetterauer, 1986). However, no increase was observed in the recovery of fructose or $\mathrm{N}$ acetylamino sugar levels in the coagulum-prostatic fluid mixture after the hydrolysis of protein (i.e. $3 \mathrm{mg} / \mathrm{ml} / \mathrm{h}$ : see Table 2) which is similar to that of fresh ejaculates with normal coagulation/ liquefaction properties (Mandal \& Bhattacharyya, 1985b). These observations therefore indicate that these substances are instantly removed from the coagulum by washing and eliminate their involvement as an integral part of the coagulum.

Human seminal sialic acid and amino sugar exist mainly (90-98\%) in the bound form (Karagiannidis, 1972; Mandal \& Bhattacharyya, 1990) and can be quantitated after complete acid hydrolysis of the washed coagulum and semen. The demonstration of sialic acid and amino sugar in the washed coagulum by $25 \%$ of the total content as integral parts and the qualitative evidence presented elsewhere (Kusamran \& Surakarnkul, 1983; Wongkome \& Chulavatnatol, 1984) indicate that sialoglycoproteins are associated with the coagulum structure of human semen. The existence of vesicular components in soluble and insoluble forms suggest that, for critical evaluation of seminal vesicular activity from semen, measurements of at least one of the soluble markers (e.g. fructose, $\mathrm{N}$-acetylamino sugar, phosphate) along with the percentage coagulum in fresh ejaculate (Mandal \& Bhattacharyya, 1988a) are essential.

This work was supported by grants from the Indian Council of Medical Research, New Delhi, and the Council of Scientific and Industrial Research.

\section{References}

Amelar, R.D. (1962) Coagulation, liquefaction and viscocity of human semen. J. Urol. 87, 187-190.

Arver, S. (1982) Studies on zinc and calcium in human seminal plasma. Acta physiol. scand., Suppl. 507, I-21.

Beyler, S.A. \& Zaneveld, L.J.D. (1982) The male accessory sex glands. In Biochemistry of Mammalian Reproduction, pp. 65-88. Eds L. J. D. Zaneveld \& R. T. Chatterton. John Wiley \& Sons, New York

Bostrom, K. \& Andersson, L. (1971) Creatine phosphokinase relative to acid phosphatase, lactate dehydrogenase, zinc and fructose in human semen with special reference to chronic prostatitis. Scand. $J$. Urol. Nephrol. 5, 123-132.

Karagiannidis, A. (1972) Observations on the state of sialic acid in human and bovine seminal plasma. $J$. Reprod. Fert. 28, 121-123.

Kavanagh, J.P. (1983) Zinc binding properties of human prostatic tissue, prostatic secretion and seminal fluid. J. Reprod. Fert. 68, 359-363.
Kavanagh, J.P. (1985) Sodium, potassium, calcium, magnesium, zinc, citrate and chloride content of human prostatic and seminal fluid. J. Reprod. Fert. $75,35-41$

Koren, E. \& Lukač, J. (1979) Mechanism of liquefaction of the human ejaculate. I. Changes of the ejaculate proteins. J. Reprod. Fert. 56, 493-499.

Kusamran, T. \& Surakarnkul, R. (1983) Acid-extracted glycoproteins in human seminal coagulum. Andrologia $15,386-391$

Lilja, H. \& Laurell, C.-B. (1984) Liquefaction of coagulated semen. Scand. J. clin. Lab. Invest. 44, $447-452$.

Lilja, H. \& Laurell, C.-B. (1985) The predominant protein in human seminal coagulate. Scand. J. clin. Lab. Invest. 45, 635-641.

Lilja, H. \& Weiber, H. (1984) Synthetic protease inhibitors and post ejaculatory degradation of human semen proteins. Scand. J. clin. Lab. Invest. 44, 433-438. 
Lilja, H., Oldbring, J., Rannevik, G. \& Laurell, C.-B. (1987) Seminal vesicle-secreted proteins and their reactions during gelation and liquefaction of human semen. J. clin. Invest. 80, 281-285.

Mandal, A. \& Bhattacharyya, A.K. (1985a) Studies on the coagulational characteristics of human ejaculates. Andrologia 17, 80-86.

Mandal, A. \& Bhattacharyya, A.K. (1985b) Some preliminary observations on the liquefaction of human semen. Andrologia 17, 228-233.

Mandal, A. \& Bhattacharyya, A.K. (1985c) Physical properties and non-enzymic components of human ejaculates. Relationship to spontaneous liquefaction. Int. J. Androl. 8, 224-231.

Mandal, A. \& Bhattacharyya, A.K. (1986a) Human seminal antiliquefying agents-a potential approach towards vaginal contraception. Contraception 33, 31-38.

Mandal, A. \& Bhattacharyya, A.K. (1986b) Grouping of human ejaculates according to the degree of coagulation and the relationship to the levels of choline and cholinesterase. Int. J. Androl. 9, 407-415.

Mandal, A. \& Bhattacharyya, A.K. (1987a) A simple method to identify the vesicular and prostatic origin of human seminal components. Acta europ. fertil. 18, 213-216.

Mandal, A. \& Bhattacharyya, A.K. (1987b) Phosphate, zinc, calcium, citric acid and acid phosphatase in human ejaculates as related to coagulation/ liquefaction. Archs Androl. 19, 275-283.

Mandal, A. \& Bhattacharyya, A.K. (1987c) Relationship between the coagulation-liquefaction property of human ejaculates and their volume, sperm count and motility. Clin. Reprod. Fertil. 5, 367-371.

Mandal, A. \& Bhattacharyya, A.K. (1988a) Differences in osmolality, pH, buffering capacity, superoxide dismutase and maintenance of sperm motility in human ejaculates according to the degree of coagulation. $I n t$. J. Androl. 11, 45-51.

Mandal, A. \& Bhattacharyya, A.K. (1988b) Biochemical parameters of slowly liquefying human ejaculates. Archs Androl. 20, 141-146.

Mandal, A. \& Bhattacharyya, A.K. (1990) Amino sugar levels in normally coagulating and poorly coagulating human ejaculates. Int. J. Fert. (in press).

Molnar, J., Biro, J. \& Berenyi, M. (1971) Certain components of the seminal fluid without the secretion of the seminal vesicle. Fert. Sieril. 22, 462-467.

Montagnon, D., Clavert, A. \& Cranz, C. (1982) Fructose, proteins and coagulation in human seminal plasma. Andrologia 14, 434-439.

Nahoum, C.R.D. \& Cardozo, D. (1980) Staining for volumetric count of leukocytes in semen and prostate-vesicular fluid. Fert. Steril. 34, 68-69.

Richterich, R. (1969) Clinical Chemistry, Theory and Practice, pp. 17-35. S. Karger, Basel.

Tauber, P.F., Propping, D. \& Zaneveld, L.J.D. (1978) The seminal coagulum. In Scanning Electron Microscopy of Human Reproduction, pp. 69-88. Ed E. S. E. Hafez. Ann Arbor Science Publishers Inc.. Ann Arbor.

Wagner, W.D. (1979) A more sensitive assay discriminating galactosamine and glucosamine in mixtures. Analyt. Biochem. 94, 394396.

Wetterauer, U. (1986) Recommended biochemical parameters for routine semen analysis. Urol. Res. 14, 241--246.

Wongkome, C. \& Chulavatnatol, M. (1984) Sialoglycoproteins of ejaculated human spermatozoa and seminal plasma. Int. J. Androl. 7, 352-361.

Received 7 March 1989 